\title{
Mushroom worker's lung
}

\author{
E D W AR D J ACKSON, K. M.A. WELCH \\ The Royal Hospital, West Street, Sheffield
}

Two cases of an acute chest illness occurring in mushroom workers are described. In one patient, who was severely ill, a lung biopsy was obtained which showed a pattern of alveolitis and interstitial fibrosis. The serum of both patients gave a precipitin reaction to an extraction of mushroom compost after spawning, but no reaction occurred to a variety of hay antigens used in the diagnosis of farmer's lung. A provocation test undertaken in one patient demonstrated a reaction to the inhalation of a dilute extract of mushroom compost after spawning. The most severely ill patient made a full clinical and functional recovery without steroid therapy.

Allergic alveolitis has been described in recent years as an occupational hazard of mushroom workers (Sakula, 1967; Bringhurst, Byrne, and Gershon-Cohen, 1959). We wish to describe two patients with this condition, one exceptionally ill, in whom lung and liver biopsy material was examined.

\section{CASE REPORTS}

CASE 1 A man of 58 developed increasing breathlessness and tight upper chest pain after a period of six weeks' employment in the spawning process of mushroom farming. In addition he complained of cough, gross weight loss, rigors, and night sweats.

On admission to hospital he was pyrexial $\left(100^{\circ} \mathrm{F}\right.$.), markedly wasted, and dyspnoeic at rest with central cyanosis. Extensive fine crepitations were heard in the chest. The liver edge was palpable one fingerbreadth below the costal margin. No other abnormality was noted.

Investigations Chest radiography showed extensive nodular opacification, confluent in some areas (Fig. 1).

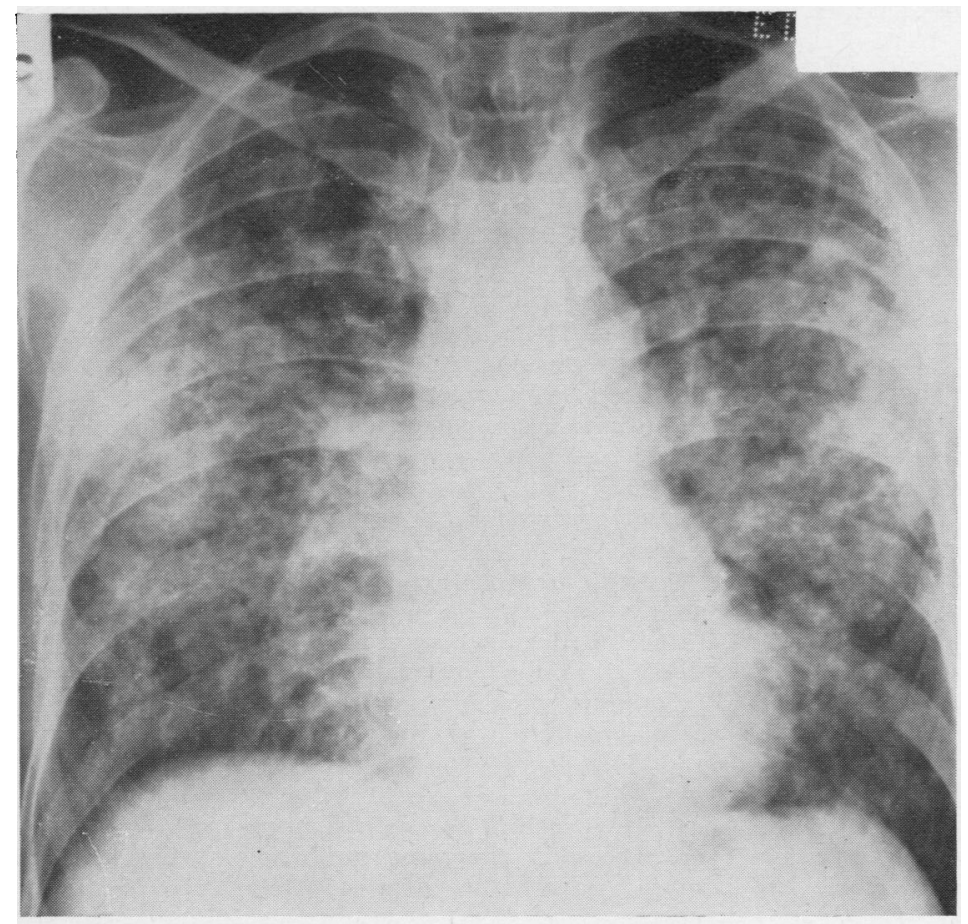

FIG. 1. Case 1. Chest radiograph on admission showing widespread nodular opacities, confluent in some areas. 


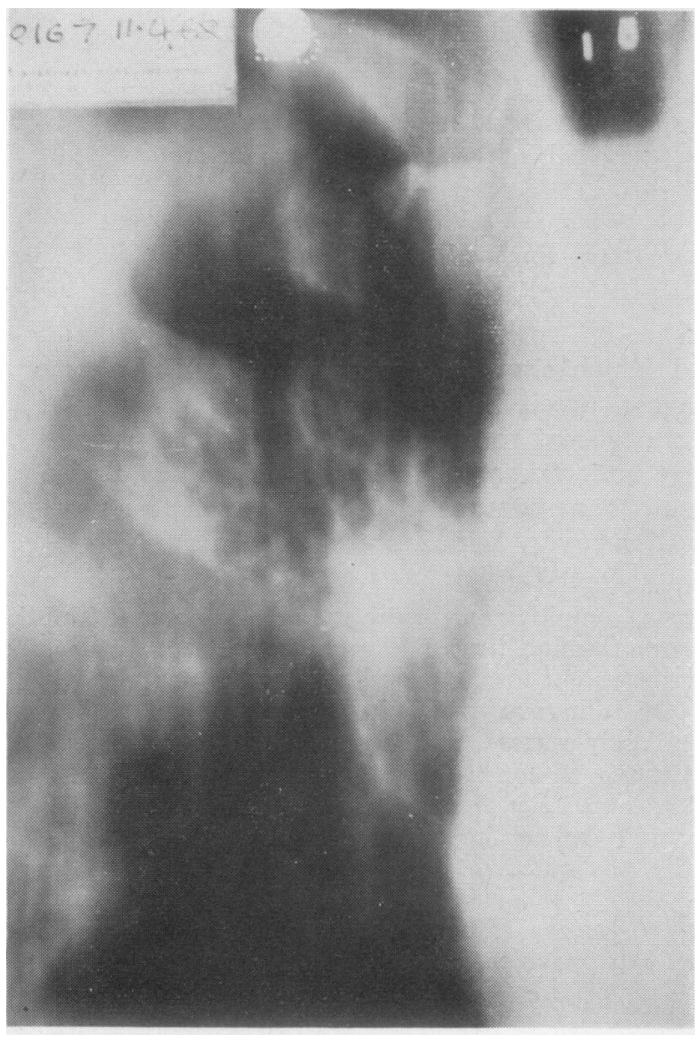

FIG. 2. Case 1. Tomogram of the most seriously affected area in the right upper lobe, showing apparent cystic spaces.

Tomography suggested cyst formation in the most seriously affected area (Fig. 2). Sputum: no acid fast bacilli demonstrated. Mantoux testing 1:10,000 negative, $1: 100$ positive ; haemoglobin $104 \%$, E.S.R. 57 $\mathrm{mm}$. in one hour (Westergren). Liver function: bilirubin $1.2 \mathrm{mg}$., thymol flocculation and turbidity negative, S.G.O.T. $120 \mathrm{King}$ units, S.G.P.T. $150 \mathrm{King}$ units, alkaline phosphatase $26 \mathrm{King}$ units. A moderate excess of urobilin and urobilinogen was found in the urine. Serum proteins: total $5.8 \mathrm{~g} . \%$, albumin $2.15 \mathrm{~g}$., globulins: alpha $10.66 \mathrm{~g}$., alpha $21.2 \mathrm{~g}$., beta $0.55 \mathrm{~g}$., gamma $1 \cdot 3 \mathrm{~g}$. Coombs test negative.

Because of the severity of the illness and the unusual radiographic appearances. lung biopsy was performed three weeks after admission. The biopsy material was taken from the worst affected area in the right upper lobe (Figs 3 and 4). This showed a severe inflammatory reaction affecting both the alveoli and the interstitial tissues. Many of the alveoli were filled with cells which had a granular P.A.S. staining cytoplasm and which resembled granular pneumocytes. In addition occasional alveolar macro- phages were present. The alveoli were lined by hyper plastic epithelial cells, apparently desquamating in areas. The alveolar walls were thickened by banas o을 fibrous tissue and there was an extensive fibrosis of the interstitial tissues. The dominant inflammators cell present in the interstitial tissue was the lymphoo cyte, with occasional plasma cells. No giant cell sys $\cong$ tems were seen. No evidence of vasculitis was noted in those vessels seen in the specimen. Respiratory function tests are shown in the Table.

T A B L E

RESPIRATORY FUNCTION

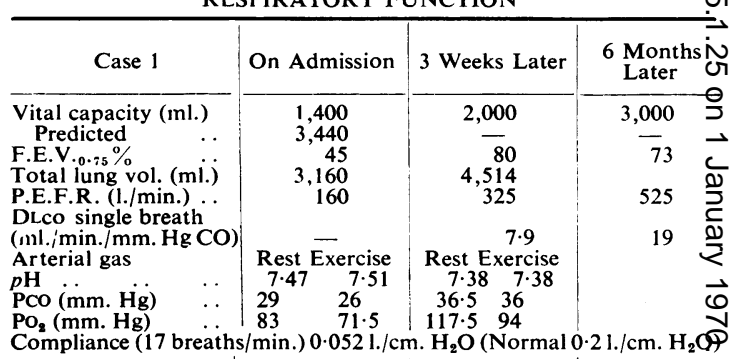

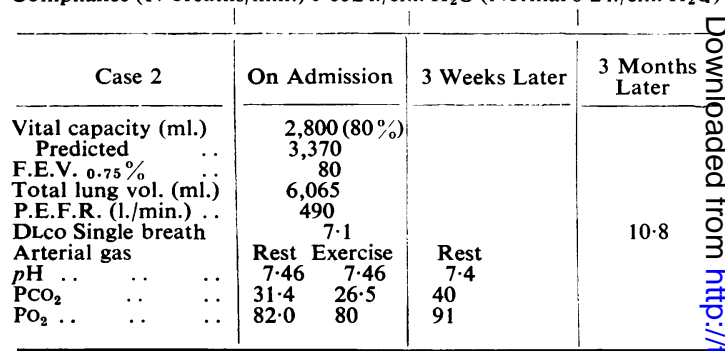

Serology: No antibodies were found to a variety of hay antigens, but there was a positive precipitin reaco tion to an extract of mushroom compost after spawn ing. When he had recovered, an inhalation test wa. undertaken with dilute saline extracts of hay an composts. There was no reaction to hay extracts of to mushroom compost before the stage of spawning? but there was a pyrexial response to a dilute extract of mushroom compost after the spawning stage. Liver. biopsy was performed because of hepatomegaly and abnormal liver function tests. This showed onls moderate centrilobular and sinusoidal venous cons gestion.

Initially he was treated with a week's course of tetracycline with no apparent improvement. N\& further therapy was given and steady improvemerf followed in the ensuing weeks. A chest radiograp角 six months after admission showed a slight reticular nodular pattern with some fibrosis in the right upper lobe (Fig. 5).

CASE 2 A man of 64 was first employed in the spawn ing process at the same mushroom farm as case ? only 19 days before admission. He had developed 


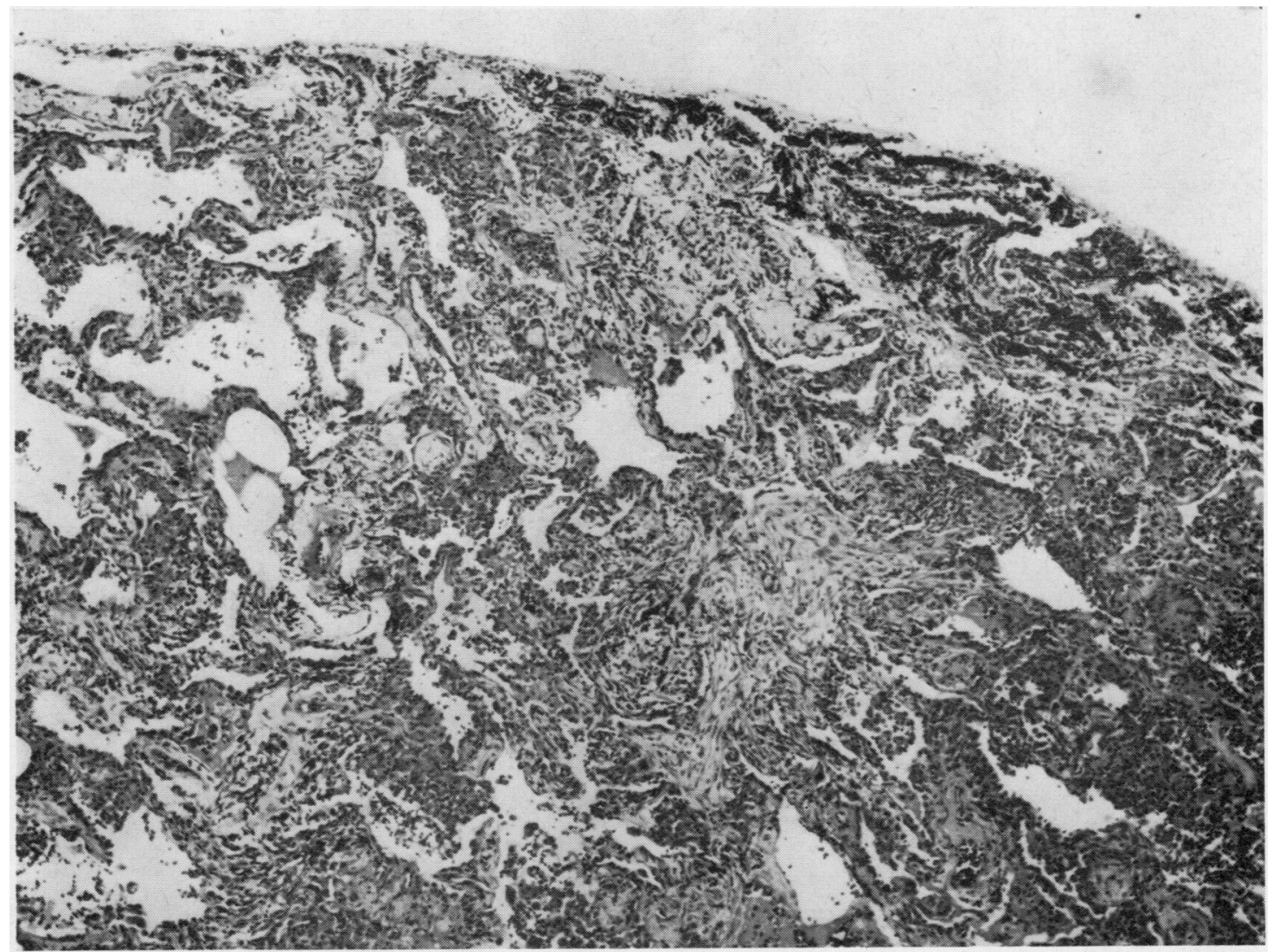

FIG. 3. Case 1. Lung biopsy. General appearance showing intra-alveolar exudate, alveolar wall fibrosis, and extensive fibrosis of the interstitial tissues $(H$. and $E . \times 115)$.

cough and increasing breathlessness. In addition he had noticed a swelling and blistering of the lips. His appetite was poor and he had lost a stone (6.3 kg.) in weight over a period of two and a half weeks. On examination he was thin and slightly cyanosed, but there was no evidence of respiratory distress. In the chest there were fine crepitations over the mid and lower zones posteriorly.

Investigations His chest radiograph showed several ill-defined opacities in the peripheral fields of both lungs, with scattered nodular shadowing (Fig. 6). His haemoglobin was $99 \%$, E.S.R. $70 \mathrm{~mm}$. in one hour (Westergren), liver function tests normal, no L.E. cells seen in the blood, latex test negative, and no sputum could be obtained for examination. His respiratory function is shown in the Table.

Serology: As in Case 1 there was no reaction to a variety of hay antigens, but there was a positive precipitin reaction to an extract of mushroom compost after spawning.

His progress has been slow so far. Although the signs in the chest resolved over a period of six weeks on no therapy, he is still breathless on effort 12 months later.

\section{DISCUSSION}

We were impressed by the severity of the illness in case 1 , and in both cases there was a serious constitutional upset with much weight loss, as in the third case described by Sakula (1967). Both patients were employed in the spawning process of mushroom cultivation. At this farm the prepared compost, which has reached a temperature as high as $130^{\circ} \mathrm{F}$., is mixed mechanically with the mushroom spawn. A fine dust is released and workers in close proximity cannot avoid inhaling some of it. 


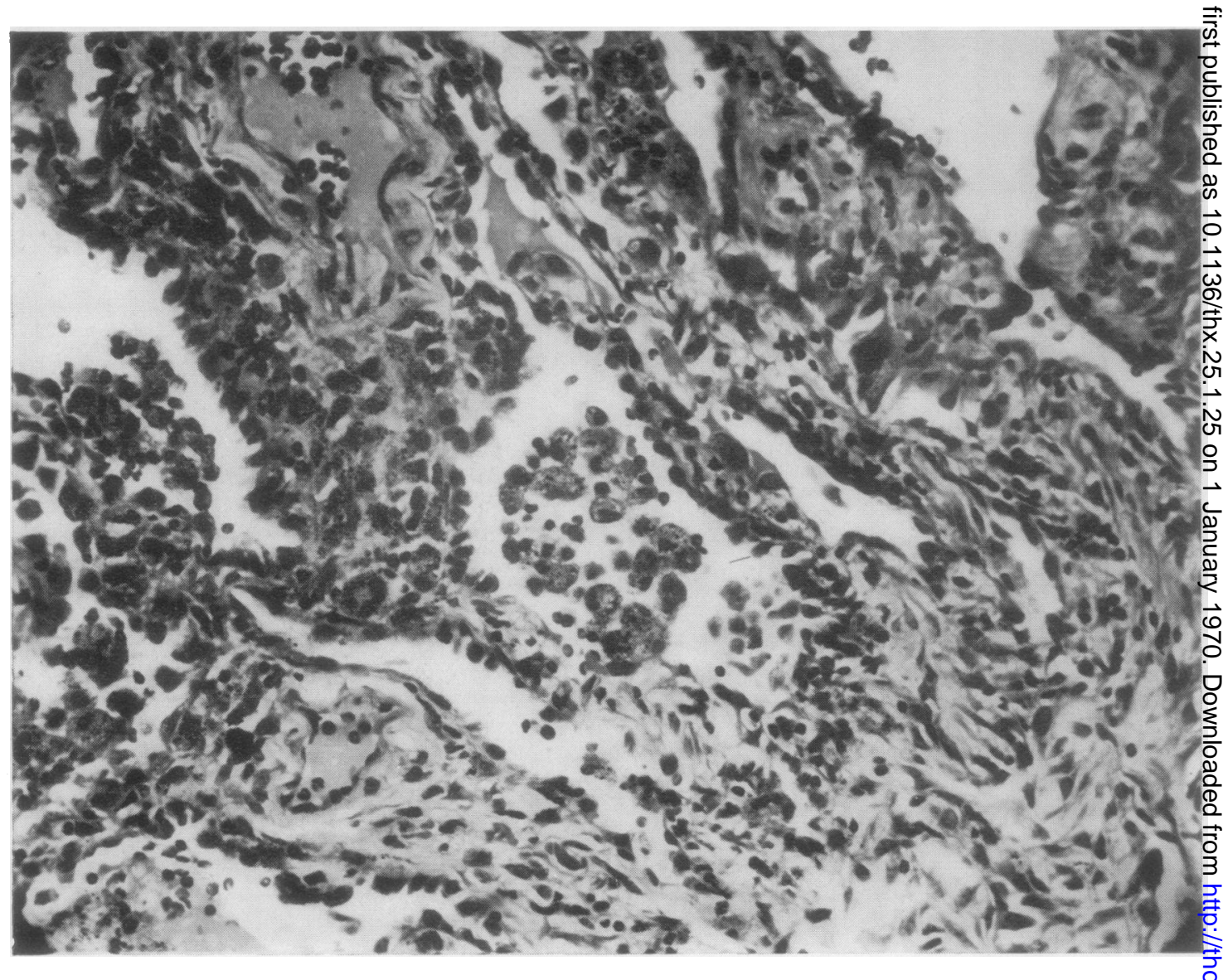

FIG. 4. Case 1. Lung biopsy. Higher power view showing intra-alveolar exudate consisting of large P.A.S. staining cells, resembling type II granular pneumocytes. There is hyperplasia of the alveolar epithelial cells $\left(H\right.$. and $E_{\text {. }}^{\times}$ $\times 430)$.

In our patients, testing for precipitin antibodies to specific thermophilic actinomycetes was negative and there was no reaction to a mixed hay antigen used in the diagnosis of farmer's lung. In both patients, however, there was a precipitin reaction to a crude extract of mushroom compost after spawning.

In our first patient, who underwent inhalation tests, the possibility of allergy to mushroom spawn is suggested by a reaction only to the extract of compost which had been spawned. It is interesting to note that two of Sakula's cases did not react to standard actinomycete antigens. It is thought that the alveolitis that develops in this disorder is caused by a precipitin mediated type III allergic reaction (Pepys, 1967). The acute oedema and blistering of the lips seen in case 2 suggests a type I allergic reaction as well.
The histological changes described in farmer's lung have generally stressed a granulomatous reo action (Dickie and Rankin, 1958 ; Seal, Hapke, Thomas, Meek, and Haynes, 1968). The histo logical features showed evidence of alveolar cel desquamation and interalveolar fibrosis and are indistinguishable from those features described inf idiopathic fibrosing alveolitis (Scadding and Hin son, 1967). So far as we are aware, this is the first instance in which lung biopsy findings hav been described in mushroom worker's lung.

The changes seen in the tests of respirator function (see Table) are typical of those seen ino this type of lung disease, namely a big reductior in the carbon monoxide diffusion capacity, hypox $\mathbb{\mathbb { Q }}$ aemia, and resulting hypocapnia with a respira霖 tory alkalosis. There was, in addition, a degree of airways obstruction. In case 1 , despite the severit 


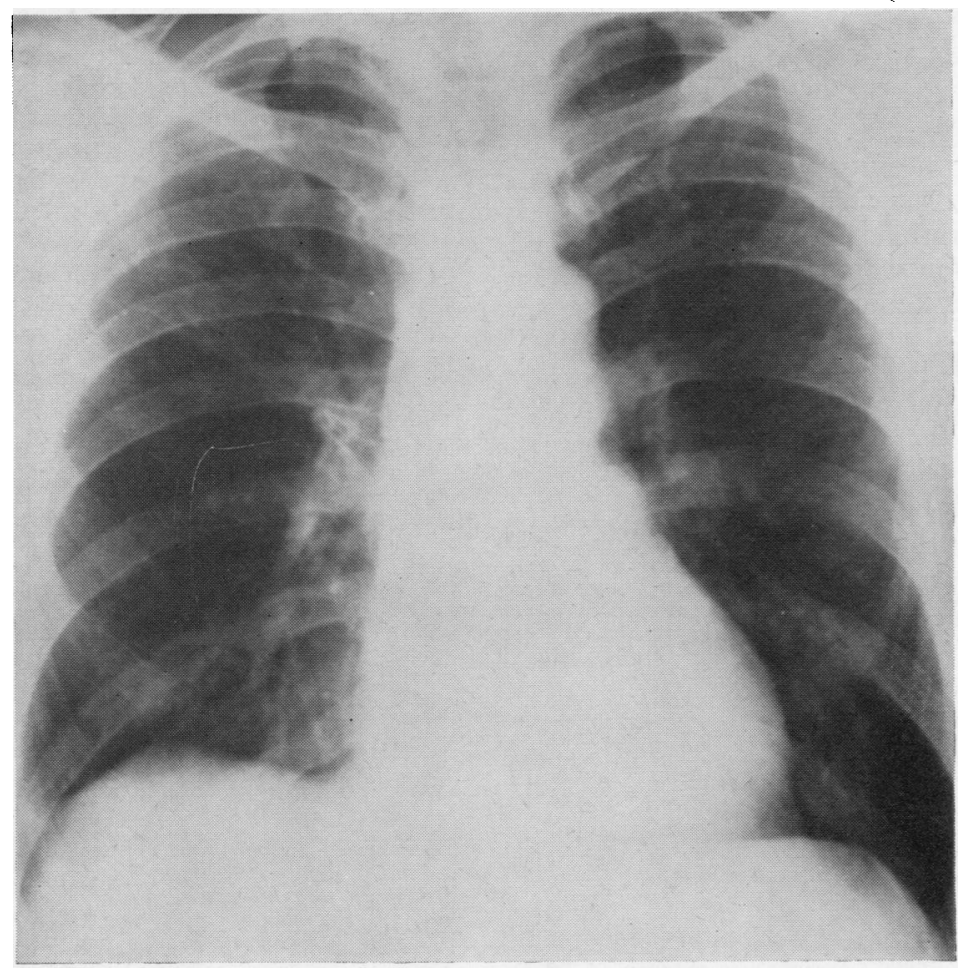

FIG. 5. Case 1. Chest radiograph six months after admission, showing almost complete clearing.

FIG. 6. Case 2. Chest radiograph on admission, showing scattered ill-defined nodular opacities.

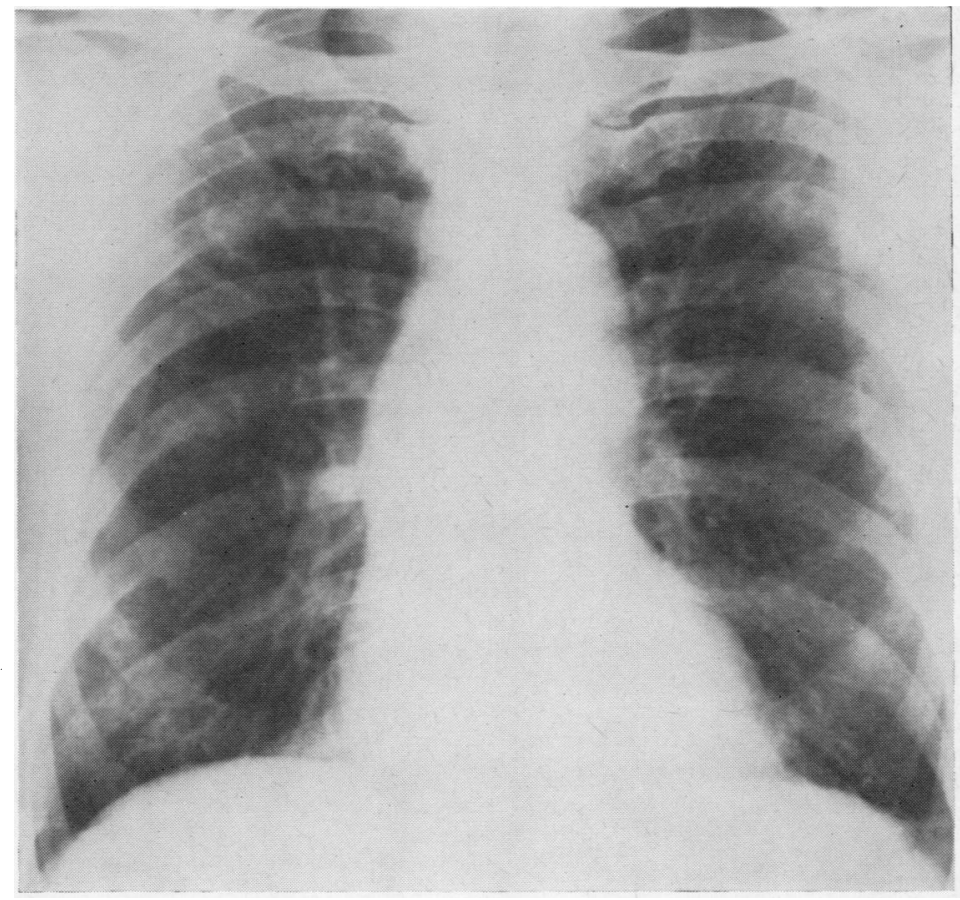


of the disease process, there was a remarkable improvement in the $\mathrm{CO}$ diffusion capacity over a period of six months.

Turner-Warwick (1968) has described an association of chronic liver disease with idiopathic fibrosing alveolitis; the liver biopsy appearances generally showed lymphocytic infiltration. Case 1 showed a disturbance of liver function which was presumably attributable to venous congestion, noted on the liver biopsy.

Since the inflammatory reaction in the lung biopsy was so severe, steroid therapy may seem to have been indicated, but by the time of the biopsy the patient was beginning to improve. The return of both radiographic and lung function to near normal shows that steroid therapy is not essential. Presumably the withdrawal from the antigenic environment is the most important factor.
Our thanks are due to Dr. T. E. Gumpert, under $\stackrel{\vec{F}}{\vec{S}}$ whose care both patients were admitted, to Professor 0 J. Pepys and Dr. F. E. Hargreaves for serological testing and advice, to Drs. T. W. Astin, P. Howard, and I. F. Webster, of the Department of Medicine, for $\vec{\nabla}$ the investigation of pulmonary physiology, and to Dr. $\varrho$ L. Henry, Department of Pathology, Royal Hospital, Sheffield.

\section{REFERENCES}

Bringhurst, L. S., Byrne, R. N., and Gershon-Cohen, J. (1959). $\vec{\omega}$ Respiratory disease of mushroom workers. J. Amer. med. Ass., 171, 15.

Dickie, H. A., and Rankin, J. (1958). Farmer's lung: an acute granulomatous interstitial pneumonitis occurring in agricultural lomatous interstitial pneumonitis occurring in agricultural No
workers. Ibid., 167, 1069.

Pepys, J. (1967). Hypersensitivity to inhaled organic antigens. J. roy. Coll. Phycn; Lond., 2, 42.

Sakula, A. (1967). Mushroom-worker's lung. Brit. med. J., 3, 708. ज

Scadding, J. G., and Hinson, K. F. W. (1967). Diffuse fibrosing alveolitis. Thorax, 22, 291.

Seal, R. M. E., Hapke, E. J., Thomas, G. O., with Meek, J. C., and Haynes, M. (1968). The pathology of the acute and chronic Haynes, M. (1968). The pathology
stages of farmer's lung. Ibid., $23,469$.

Turner-Warwick, M. (1968). Fibrosing alveolitis and chronic liver disease. Quart. J. Med., 37, 133. 